\title{
Infrastructure Asset Management: Referees 2016
}

The following is a list of referees who have reviewed papers for Infrastructure Asset Management between 1 December 2015 and 30 November 2016. The Institution of Civil Engineers is very grateful for their assistance.

We are continually looking for suitable reviewers for papers submitted to Infrastructure Asset Management. Papers published in the ICE journals must be submitted to at least two independent referees to judge accuracy, style, impact, importance and interest.
C Ellis

J Foster-Clark

B García de Soto

A Gibbs

P Hallsworth

T Hartmann

F Hasselmann

G Holt

R A Inglis
If you are interested in reviewing articles on any topic related to infrastructure asset management, please submit your name, qualifications or CV, and areas of expertise. We are in need of individuals who will agree to review papers in a timely fashion (within 3 to 4 weeks of receipt) and provide confidential feedback to the Editorial Advisory Panel concerning the quality of the paper and any suggested revisions that would be appropriate.

If you are such a person, please contact Agnes Alvite (tel.: +44 (0)207 665 2204; e-mail: agnes.alvite@icepublishing.uk) for more information on the referee process.

I Jenkinson
M Kakouratou
A Kirwan
D Komakech
I Krystallis
S Male
K Moodley
T Onyenobi
F Orozco

E Osaji

D Pocock

A Stainsby

T Taylor

K Tully

B Wareham

$B$ Wiegand

X-X Yuan 